\title{
Estimation of Nevirapine from Human Plasma by LC-ESI-MS/MS: a Pharmacokinetic Application
}

Chinmoy Ghosh ${ }^{1,2}$, Shashank Gaur ${ }^{1}$, Ajay Singh ${ }^{1}$, Chandrakanta P. Shinde ${ }^{2}$ and Bhaswat S. Chakraborty ${ }^{1 *}$

${ }^{1}$ Bio-analytical Department, Cadila Pharmaceuticals Limited, 1389-Trasad road, Dholka, Gujarat, India

2 Jiwaji University, School of studies in Chemistry, Gwalior, M.P., India

\begin{abstract}
A selective, sensitive, and fast High Performance Liquid Chromatography with mass spectrometric (MS) detection method was developed and validated in human plasma. Nevirapine and Enalapril (internal standard, IS) were extracted from human plasma via solid phase extraction (SPE) technique. After the elution through SPE cartridge, samples were directly analyzed using LC-ESI-MS/MS system. An isocratic mode is used to separate interference peaks using a hypurity advanced $C-18,50 \times 4.6 \mathrm{~mm} I D, 5 \mu$, column. The mobile phase composition was $0.1 \%$ formic acid in Milli-Q water (v/v) to acetonitrile at a ratio of $15: 85, \mathrm{v} / \mathrm{v}$. The $\mathrm{m} / \mathrm{z}$ of nevirapine and IS were 267.00 $/ 226.20$ and $377.10 / 234.10$, respectively. Linearity ranges were 10.00 to $5000.50 \mathrm{ng} / \mathrm{mL}$. Calibration functions, lower limit of quantitation (LLOQ), stability, intra- and inter-day reproducibility, accuracy, and recovery are estimated. This method was free from matrix effects and any abnormal ionization. This method was successfully applied to a pharmacokinetic study of nevirapine.
\end{abstract}

Keywords: Nevirapine; Solid phase extraction; Matrix effects; Method validation; Liquid-liquid extraction; Protein precipitation; Pharmacokinetic

\section{Introduction}

Nevirapine (NVP) (Figure 1) is a non-nucleoside reverse transcriptase inhibitor (NNRTI) that binds to the membrane of the HIV virus inhibiting viral replication. It also probably inactivates cellfree virions present in the genital tract and in human milk. It is best used synergistically with at least one nucleoside reverse transcriptor inhibitor (NRTI) drug - the most widely studied of which is zidovudine (q.v.). Nevirapine is well absorbed by mouth, widely distributed (VD $1.21 / \mathrm{kg}$ ), penetrates the CSF well and, because it is lipophilic, rapidly transferred across the placenta. A substantial quantity appears in breast milk. There is no evidence of teratogenicity. It is extensively metabolised by the cytochrome P450 isoenzyme system in the liver with a half life of 40-60 hours when treatment is first started - a half life that is almost halved by enzyme autoinduction after 1-2 weeks. It is also reduced in patients on rifampicin, but extended in patients taking a range of other drugs including cimetidine, erythromycin, and fluconazole. The most important adverse effects occasionally seen with sustained use are a skin rash (which is sometimes severe) and liver dysfunction (which is reversible if treatment is topped). Nevirapinee is used to prevent the babies of human immunodeficiency virus (HIV) infected women becoming infected during delivery. Some babies born to women whose infectious status is unknown may also merit treatment. Twice weekly use may reduce the risk of infection during lactation, but resistance soon develops during monotherapy. Combined treatment with zidovudine (q.v.) costs more, but further reduces viral transmission, and may make later drug resistant less likely [1-6].

Several HPLC [7-14] and LC-MS/MS [15-18] methods are available for estimation of nevirapine from human plasma. Among all these reported methods only one method i.e Laurito et. al. [18] has a LLOQ value of $10 \mathrm{ng} / \mathrm{mL}$, and other methods have LLOQ values ranging from $25-250 \mathrm{ng} / \mathrm{mL}$. The analysis time of each single run for the method published by Laurito et. al. was 5 mins, whereas, in this present manuscript the analysis time is only 3 mins. So, Laurito et. al. has achieved the sensitivity by compromising with analysis time. The injection volume in the present manuscript is $5 \mu \mathrm{L}$ only, so by increasing the injection volume more sensitivity can also be achieved. Simple solid phase extraction (SPE) technique is used to extract nevirapine from human plasma which gives cleaner sample than liquid-liquid extraction or protein precipitation. After elution the sample was directly injected into LC-MS/MS without any evaporation step, which is an easy and fast sample preparation technique. So, in comparison with all other published methods, the present manuscript describes a method with highest sensitivity and maximum throughput.

\section{Experiment}

\section{Apparatus and software}

The HPLC system with an auto sampler was a Shimadzu LC-

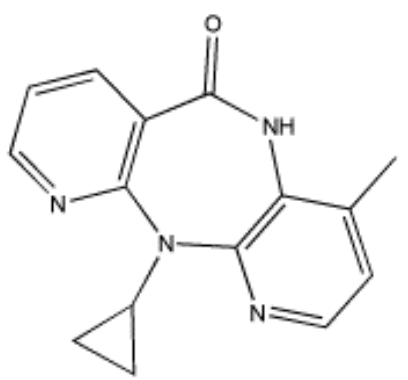

Figure 1: Chemical structure of nevirapine.

${ }^{*}$ Corresponding author: Dr. Bhaswat S. Chakraborty, Sr. Vice President, Bioanalytical Department, Contract Research Organization, Cadila Pharmaceuticals Limited, 1389, Trasad road, Dholka-387 810, Dist: Ahmedabad, Gujarat, India, Tel: +91-2714-221481/83/84 Ext. 107; Fax: +91-2714-221848; Email: drb. chakraborty@cadilapharma.co.in

Received January 05, 2011; Accepted January 24, 2011; Published February 08, 2011

Citation: Ghosh C, Gaur S, Singh A, Shinde CP, Chakraborty BS (2011) Estimation of Nevirapine from Human Plasma by LC-ESI-MS/MS: a Pharmacokinetic Application. J Bioequiv Availab 3: 020-025. doi:10.4172/jbb.1000052

Copyright: ( 2011 Ghosh C, et al. This is an open-access article distributed unde the terms of the Creative Commons Attribution License, which permits unrestricted use, distribution, and reproduction in any medium, provided the original author and source are credited. 
10ADvp (Shimadzu, Japan) coupled with Applied Biosystem Sciex (MDS Sciex, Canada) API 3000 Tandem mass spectrometer. The auto sampler was SIL-HTC from Shimadzu, Japan. The solvent delivery module was LC-20AD from Shimadzu, Japan. The chromatographic integration was performed by Analyst software (version: 1.4.2; Applied Biosystems). Positive pressure unit used for SPE was from Orochem technologies Inc (Lombard, IL, USA).

\section{Chemicals and reagents}

Nevirapine and enalapril (IS) were procured from Cadila Pharmaceutical Ltd., Dholka, Ahmedabad, India. Formic acid was procured from Merck Specialities Pvt. Ltd, Mumbai, India. Water used was collected from water purification systems (Milli Q, Milli Pore, USA) installed in laboratory. Methanol and acetonitrile were of HPLC grade and were supplied by J. T. Baker, USA. Fresh frozen human plasma ( $\mathrm{K}_{2}$-EDTA as anticoagulant) was used during validation and study sample analysis, and was supplied by Clinical department of Cadila Pharmaceuticals Limited, 1389-Trasad road, Dholka, Gujarat, India. Plasma was stored into $-70 \pm 5^{\circ} \mathrm{C}$.

\section{Standards and working solutions}

Individual stock standard solution of NVP and IS containing $1 \mathrm{mg} / \mathrm{mL}$ was prepared by dissolving pure compound in methanol. The intermediate and working solutions of NVP were prepared from corresponding stock solutions by diluting with diluent (Water: Methanol 30:70 v/v). Calibration standards were established between 10.00 to $5000.50 \mathrm{ng} / \mathrm{mL}$ of using nine concentration levels. Quality control (QC) standards of three different levels low (LQC) $(30.00 \mathrm{ng} /$ $\mathrm{mL}$ ), medium (MQC) (2400.25 ng/mL) and high (HQC) (3900.40 ng/ $\mathrm{mL}$ ) were also prepared. All these stock solutions, calibration standards and QC samples were stored at $4 \pm 2^{\circ} \mathrm{C}$. These solutions were found to be stable and used for the complete method validation.

\section{Chromatographic conditions}

Chromatographic separation was performed on a Hypurity advance C18, $50 \times 4.6 \mathrm{~mm}$ ID, $5 \mu$, analytical column and the mobile phase was a mixture of $0.10 \%(\mathrm{v} / \mathrm{v})$ formic acid in water to acetonitrile at a ratio of $15: 85, \mathrm{v} / \mathrm{v}$. Injection volume was $5 \mu \mathrm{L}$. The flow rate was $0.500 \mathrm{~mL} /$ min. Total analysis time of single injection was 3.00 minutes. Column oven temperature and auto sampler temperature was set to $40^{\circ} \mathrm{C}$ and $5^{\circ} \mathrm{C}$, respectively.

\section{Mass Spectrometric conditions}

The plasma NVP concentrations were quantified using SCIEX API 3000 LC-MS/MS system (MDS Sciex, Canada), equipped with an ESI interface used to generate positive ions $[\mathrm{M}+\mathrm{H}]^{+}$. The optimized ion spray voltage and temperature were set at $4000 \mathrm{~V}$ and $400^{\circ} \mathrm{C}$. The typical ion source parameters, viz., declustering potential, collision energy, entrance potential, focusing potential and collision cell exit potential were 50, 39, 15, 400 and $16 \mathrm{~V}$ for NVP and 50, 25, 10, 300 and $10 \mathrm{~V}$ for the IS, respectively. Nitrogen gas was used as gas 1 , gas 2 , curtain gas and collision-activated dissociation gas, which were set at 12, 8000, 6 and 12 psi, respectively. Quantification was performed by multiple reaction monitoring of the protonated precursor ion and the related product ion for NVP using the IS method with a peak area ratios and a linear least-squares regression curve with weighting factor of $1 / \mathrm{x}^{2}$. The mass transitions used for NVP and the IS were $\mathrm{m} / \mathrm{z} 267.00 \rightarrow$ 226.20 and $\mathrm{m} / \mathrm{z} 377.10 \rightarrow 234.10$ respectively, with a dwell time of 300 ms per transition. Quadrupoles Q1 and Q3 were set on unit resolution. The analytical data were processed by Analyst software (Version 1.4.2; Applied Biosystems).

\section{Preparation of extracted samples}

Solid phase extraction technique was used to extract the NVP from human plasma samples. $20 \mu \mathrm{L}$ of IS $(5 \mu \mathrm{g} / \mathrm{mL})$ sample was added to each sample and the sample was vortexed for 15 seconds, LiChrosep Sequence $30 \mathrm{mg} / 1 \mathrm{~mL}$ SPE cartridge (Merck, India) was conditioned with $1 \mathrm{~mL}$ of methanol, followed by equilibration with $1 \mathrm{~mL}$ of Milli-Q water. Then the sample was loaded and washed two times with $1 \mathrm{~mL}$ of Milli-Q water. Then the cartridge was dried under nitrogen for 1 min. and the sample was eluted with $1 \mathrm{~mL}$ of mobile phase and injected directly into LC-MS/MS system.

\section{Clinical protocol}

The bioequivalence study protocol presented in this manuscript was approved by the independent medical ethics committee of Cadila Contract Research Organization, Ahmedabad, Gujrat, India. A nonrandomized, single-treatment, single -period, single -sequence, single- dose pharmacokinetic study was conducted, during which subjects were administered a nevirapine $140 \mathrm{mg}$ capsule along with $200 \mathrm{~mL}$ of drinking water. Doses were administered after an over-night fasting of at least $10 \mathrm{~h}$. Volunteers were healthy, adult, male, human Indian subjects. A total of 20 blood samples from each volunteer were collected including a pre-dose sample prior to drug administration and after drug administration at $0.50,1.00,1.50,2.00,2.50,3.00,3.50,4.00$, $4.50,5.00,5.50,6.00,8.00,10.00,12.00,16.00,24.00,48.00$, and $72.00 \mathrm{~h}$.

\section{Results and Discussions}

\section{Optimization of chromatographic condition and sample cleanup}

The successful analysis of the analyte in biological fluids using LC-MS/MS relies on the optimization of chromatographic conditions, sample preparation techniques, chromatographic separation and post column detection, etc $[19,20]$. Thus, for better selectivity and sensitivity different types of columns and mobile phases were used. The length of the column varied from $50 \mathrm{~mm}$ to $150 \mathrm{~mm}$, and the particle size varied from $3.5 \mu$ to $5 \mu$. Columns of different stationary phases like C8, C18, cyano etc were used which demonstrated significant effects on peak shape. Both the peaks were eluted early in cyano columns, whereas the use of $\mathrm{C} 8$ resulted in poor peak shape. Finally, a Hypurity advanced $\mathrm{C} 18,50 \mathrm{X} 4.6 \mathrm{~mm}$ ID, analytical column of $5 \mu$ particle sizes was selected for analysis.

The influences of strength of the buffer, $\mathrm{pH}$ and different organic modifier on the signal intensities were also studied. Based on the peak intensity and matrix effects NVP and IS, $0.1 \%$ formic acid (v/v) and acetonitrile $(15: 85, \mathrm{v} / \mathrm{v})$ as mobile phase at a flow rate of $0.500 \mathrm{~mL} / \mathrm{min}$ were selected for further studies. Initially, $70 \%$ acetonitrile: $30 \%$ of $0.1 \%$ formic acid $(\mathrm{v} / \mathrm{v})$ at a flow rate of $0.500 \mathrm{~mL} / \mathrm{min}$ was tried. However, this proportion of organic phase led to peak deformation. Therefore, the 15:85 (v/v) buffer to organic phase were selected as optimum.

Different extraction techniques were tried to extract NVP from plasma samples. NVP was extracted by using protein precipitation, liquid-liquid extraction and solid phase extraction. Methanol and acetonitrile were used as precipitating agent separately, whereas, ethyl acetate was used as liquid-liquid extraction solvent. It showed matrix effects in precipitation and liquid-liquid extraction technique, whereas, no matrix effects were observed in SPE technique. Finally, solid phase extraction technique was adopted. In this method different cartridges were tested, but except LiChrosep Sequence $30 \mathrm{mg} / 1 \mathrm{~mL}$, other cartridges showed inconsistent recovery. So to get the optimum 
Citation: Ghosh C, Gaur S, Singh A, Shinde CP, Chakraborty BS (2011) Estimation of Nevirapine from Human Plasma by LC-ESI-MS/MS: a Pharmacokinetic Application. J Bioequiv Availab 3: 020-025. doi:10.4172/jbb.1000052

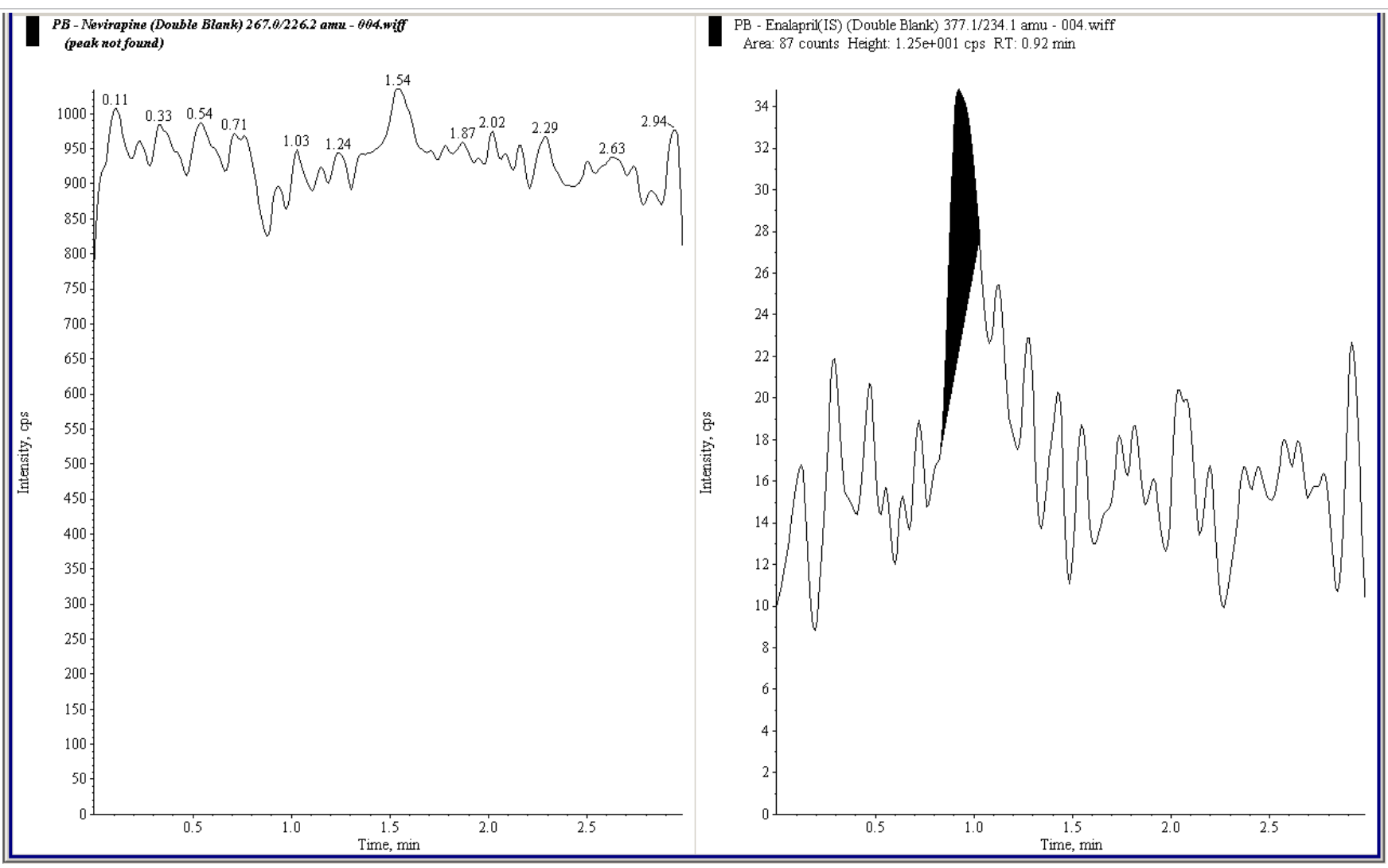

Figure 2: Representative chromatogram of plasma blank.

\begin{tabular}{|c|c|c|c|c|}
\hline \multirow{4}{*}{ Day 1} & QC Levels & Concentration (ng/mL) & Mean accuracy & Mean Precision (\% CV) \\
\hline & LQC & 30.00 & 106.21 & 4.21 \\
\hline & MQC & 2400.25 & 89.09 & 1.72 \\
\hline & $\mathrm{HQC}$ & 3900.40 & 92.07 & 5.18 \\
\hline \multirow{3}{*}{ Day 2} & LQC & 30.00 & 108.66 & 2.62 \\
\hline & MQC & 2400.25 & 111.34 & 3.38 \\
\hline & HQC & 3900.40 & 108.96 & 1.78 \\
\hline \multirow{3}{*}{ Day 3} & LQC & 30.00 & 94.78 & 3.52 \\
\hline & MQC & 2400.25 & 100.25 & 5.94 \\
\hline & $\mathrm{HQC}$ & 3900.40 & 99.3 & 5.89 \\
\hline
\end{tabular}

Table 1: Inter and intra-day accuracy and precision of nevirapine.

\begin{tabular}{|c|c|c|c|c|c|c|c|}
\hline Analyte name & QC Levels & Nominal conc. ( $\mathrm{ng} / \mathrm{mL}$ ) & $\mathbf{N}$ & Mean conc. (ng/ mL) & $\operatorname{SD}( \pm)$ & $\%$ RSD & $\%$ Accuracy \\
\hline Nevirapine & \begin{tabular}{|l|} 
LQC \\
MQC \\
HQC
\end{tabular} & \begin{tabular}{|l|}
30.00 \\
2400.25 \\
3900.40
\end{tabular} & $\begin{array}{l}18 \\
18 \\
18\end{array}$ & \begin{tabular}{|l|}
30.60 \\
2390.03 \\
3904.75 \\
\end{tabular} & \begin{tabular}{|l|}
2.203 \\
240.097 \\
323.009
\end{tabular} & \begin{tabular}{|l|}
7.20 \\
10.05 \\
8.27
\end{tabular} & \begin{tabular}{|l|}
102.01 \\
99.57 \\
100.11
\end{tabular} \\
\hline
\end{tabular}

Table 2: Overall statistics of QC samples of precision and accuracy batches during.

\begin{tabular}{|c|c|c|c|c|c|}
\hline Experiment name & QC level & Mean accuracy & Mean Precision (\%CV) & $\%$ change & Stability Duration \\
\hline \multirow{2}{*}{ Bench top } & LQC & 102.89 & 3.51 & -6.28 & \multirow{2}{*}{$07 \mathrm{~h}$} \\
\hline & $\mathrm{HQC}$ & 92.12 & 2.90 & -1.07 & \\
\hline \multirow{2}{*}{ Freeze thaw } & LQC & 97.32 & 6.37 & -1.10 & \multirow{2}{*}{4 cycles } \\
\hline & $\mathrm{HQC}$ & 95.11 & 2.30 & 3.98 & \\
\hline \multirow{2}{*}{ Auto sampler } & LQC & 107.75 & 7.29 & 9.49 & \multirow{2}{*}{$32 \mathrm{~h}$} \\
\hline & $\mathrm{HQC}$ & 97.48 & 2.09 & 6.57 & \\
\hline
\end{tabular}

Table 3: Summary of stability data of nevirapine.

and consistent recovery the above mentioned extraction technique was finalized for further sample analysis.

\section{Method validation}

A full validation according to the USFDA guidelines [22] was performed for the assay in human plasma.
Aqueous solution linearity: Aqueous solution linearity of calibration standards i.e. spiking solution checking was assessed by subjecting the spiked concentrations and the respective peak areas using $1 / \mathrm{X}^{2}(\mathrm{X}-$ concentration) linear least-squares regression analysis. The calibration curves had a correlation coefficient ( $r$ ) of 0.9900 or better. In aqueous solution linearity test all calibration standards accuracy were within $85-115 \%$, except LLOQ where it was $80-120 \%$. 
Specificity and selectivity: Six different lots of plasma along with one lipemic plasma and one haemolyzed plasma were analyzed to ensure that no endogenous interferences were present at the retention time of NVP and IS. Six LLOQ level samples along with plasma blank from the respective plasma lots were prepared and analyzed. In all plasma blanks, the response at the retention time of NVP was less than $20 \%$ of LLOQ response and at the retention time of IS, the response was less than $5 \%$ of mean IS response in LLOQ. (Figure 2) shows a typical chromatogram of plasma blank; (Figure 3) represents the chromatogram of LLOQ.

Accuracy and precision: For the validation of the assay, QC samples were prepared from normal plasma at three concentration levels (low, medium and high) according to the procedure mentioned in section 2.6. The respective concentrations were 30.00, 2400.25 and $3900.40 \mathrm{ng} / \mathrm{mL}$. Six replicates of each QC sample were analyzed together with a set of calibration standards. Three such precision and accuracy batches were analyzed in three different days. The obtained accuracy and precision (inter- and intra-day) data are presented in (Table 1 and Table 2). The result showed that the analytical method was accurate, as the accuracy of QCs were within the acceptance limits of $100 \pm 15 \%$ at their respective concentration levels. The precision around the mean value was never greater than $15 \%$ at any of the concentrations studied. (Figure 4) represents the chromatogram of upper limit of quantization (ULOQ).

Recovery study: Recovery was evaluated by comparing extracted QC samples of three different

levels in six replicates with aqueous samples of same level. The mean recovery at LQC level was $111.43 \%$, for MQC level was $90.06 \%$, and for HQC level was $93.81 \%$. The mean recovery of all three QC levels was $98.43 \%$ and the $\% \mathrm{CV}$ of mean recovery of all its three QC levels was11.59, where as the mean recovery of IS was $88.74 \%$ and the $\%$ CV was 4.51 .

Haemolysis effects: To determine the haemolysis effects, QC samples at all three concentration levels i.e. LQC $(30.00 \mathrm{ng} / \mathrm{mL})$, MQC $(2400.25 \mathrm{ng} / \mathrm{mL})$ and HQC $(3900.40 \mathrm{ng} / \mathrm{mL})$ were prepared from haemolyzed plasma. Six replicates of each QC sample were analyzed together with a set of calibration standard prepared in normal plasma. The average \% accuracy of LQC level was 109.68, for MQC level was 111.84 and for HQC level was 110.03 . The \%CV of LQC was 4.48 , for MQC was 1.89 and for HQC was 2.11.

Matrix effects: The effect of human plasma constituents over the ionization of NVP and IS were determined by comparing the responses of the post-extracted QC samples $(\mathrm{n}=18)$ with the response of analytes from aqueous samples at Low \& High QC concentrations. The \% accuracy for LQC was 96.96 and for HQC was 94.65, \% CV LQC and HQC was 6.38 and 2.83 respectively.

Dilution integrity: First, a dilution quality control sample (15001.50 $\mathrm{ng} / \mathrm{mL}$ ), which was three times of ULOQ, was prepared in plasma. Then six samples each of $1 / 5^{\text {th }}(3000.30 \mathrm{ng} / \mathrm{mL})$ and $1 / 10^{\text {th }}(1500.15 \mathrm{ng} / \mathrm{mL})$ dilution from the above prepared sample were processed in plasma and analyzed with freshly processed calibration standards as per the extraction method. The \% CV were found 9.01 and 0.72 for $1 / 5^{\text {th }}$ and $1 / 10^{\text {th }}$ diluted samples, respectively, and $\%$ nominal were found 100.39 and 101.62 for $1 / 5^{\text {th }}$ and $1 / 10^{\text {th }}$ diluted samples respectively.

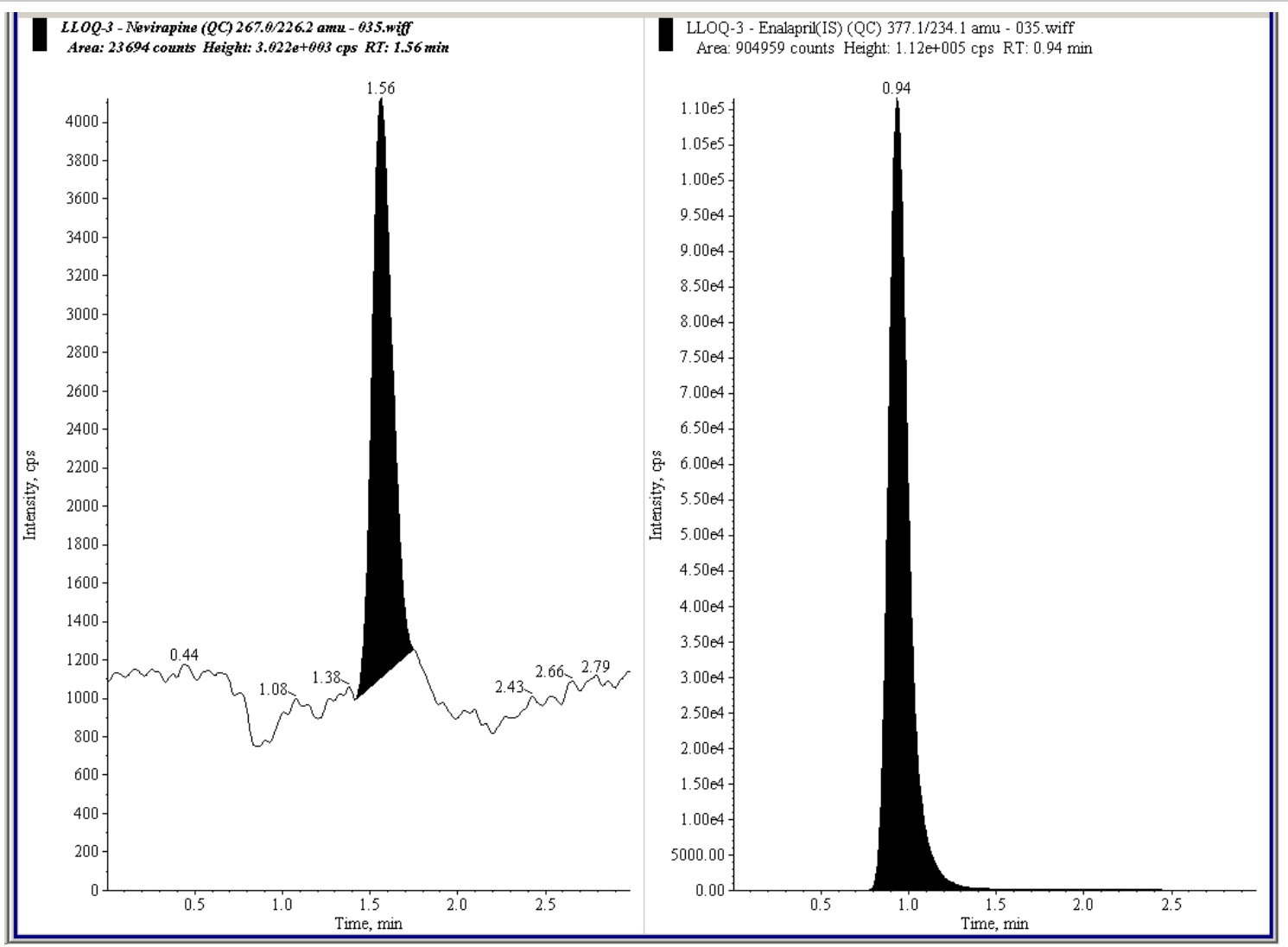

Figure 3: Representative chromatogram of lower limit of quantization (LLOQ, $10.00 \mathrm{ng} / \mathrm{mL}$ ). 
CS-1 - Nevirapine (Standard) 267.0/226.2 amu- $006 . w i$ if

Area: 4644919 counts Height: $4.93 \theta \mathrm{e}+\theta \theta 5$ cps RT: 1.57 min

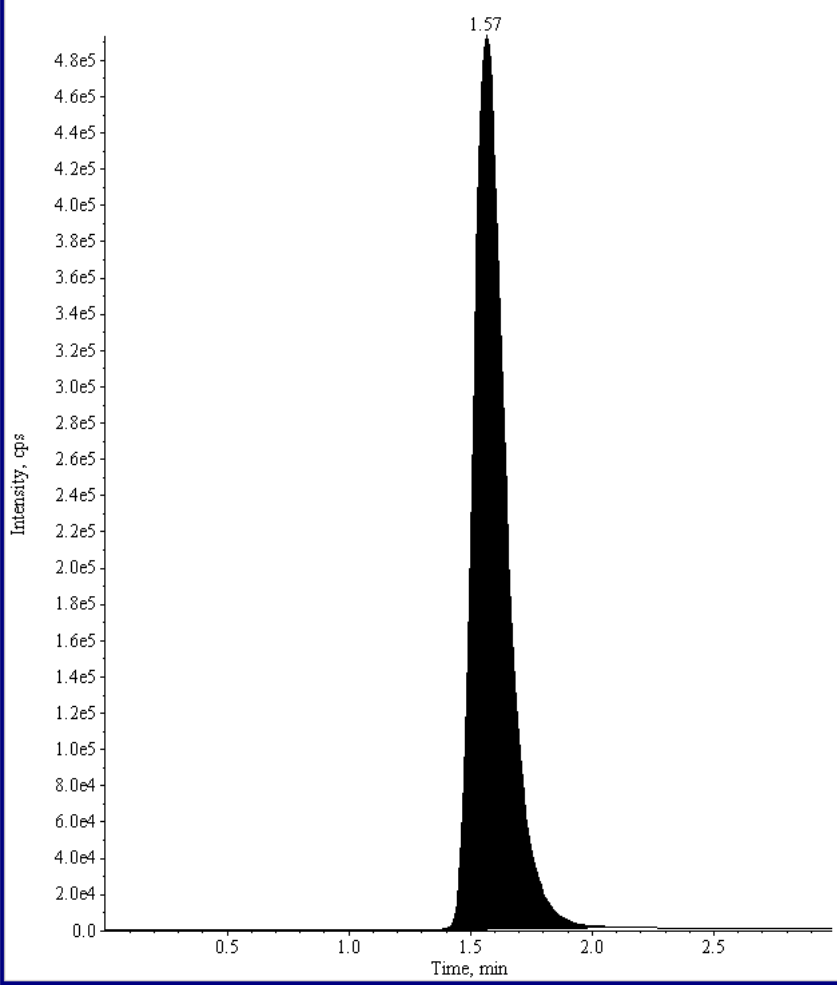

CS-1 - Enalapril(IS) (Standard) 377.1/234.1 amu - 006. wiff

Area: 895400 counts Height: $1.04 \mathrm{e}+005 \mathrm{cps}$ RT: $0.94 \mathrm{~min}$

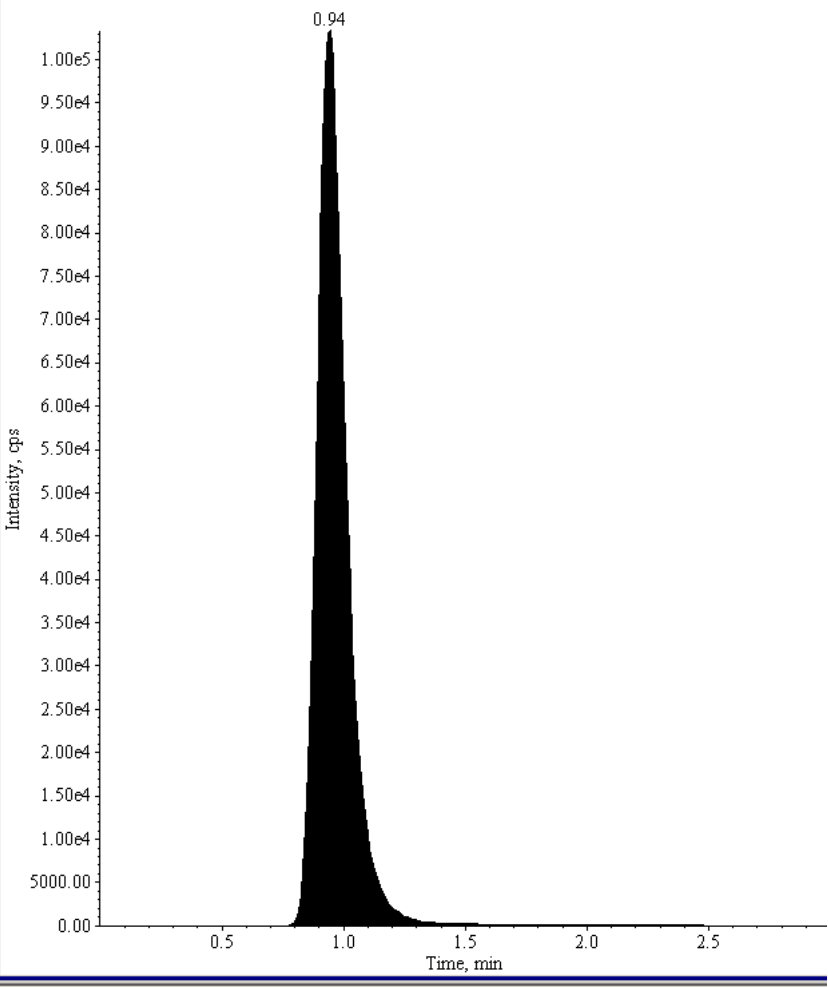

Figure 4: Representative chromatogram of upper limit of quantization (ULOQ, $5000.50 \mathrm{ng} / \mathrm{mL}$ ).

Mean Graph

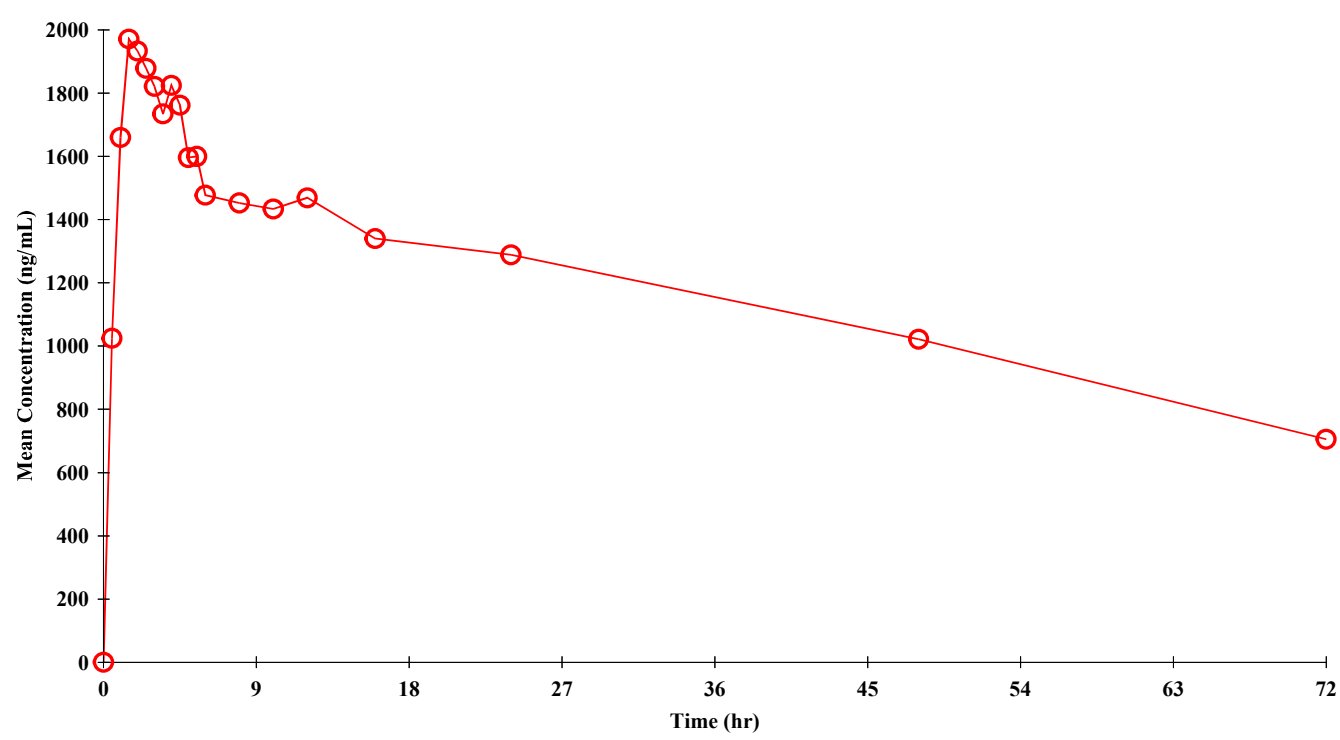

Figure 5: Representative curve of time-mean concentration profile on human volunteer.

Stability studies: The stability of NVP and IS were investigated in the stock and working solutions, in plasma during storage, during processing, after four freeze-thaw cycles, and in the final extract. Stability samples were compared with freshly processed calibration standards and QC samples. Analyte and IS were considered stable when the percent change of concentration was \pm 10 with respect to initial concentration. Summary of stability data is presented in (Table 3 ).

\section{Calibration curve}

The plasma calibration curve was prepared using nine calibration 
standards (viz. 10.00 to $5000.50 \mathrm{ng} / \mathrm{mL}$ ) according to the procedure mentioned in section 2.6. The concentration of the calibration standards are as follows: $10.00,20.00,100.00,500.05,1500.15,2500.25,3500.35$, 4000.40 and $5000.50 \mathrm{ng} / \mathrm{mL}$. The calibration curve had a reliable reproducibility over the standard concentrations across the calibration range. The calibration curve was prepared by determining the best fit of peak-area ratios (peak area analyte/peak area IS) vs. concentration, and fitted to the $y=m x+c$ using weighing factor $\left(1 / X^{2}\right)$. The average regression $(\mathrm{n}=3)$ was found to be $>0.9950$.

\section{Application}

The above described fully validated method was applied to determine the concentration- time profile, following oral administration of nevirapine in six healthy human volunteers. The $\mathrm{Cmax}$ for the product was $2050.781 \pm 368.406 \mathrm{ng} / \mathrm{mL}$ and $\mathrm{AUC}_{0-\mathrm{t}}$ was $83093.540 \pm 13414.140$ $\mathrm{ng} / \mathrm{mL} / \mathrm{h}$. Figure 5 represents the mean concentration vs time profile curve of healthy human volunteers.

\section{Conclusion}

A simple, sensitive, selective, precise and accurate LC-MS/ MS method for the determination of NVP in Human Plasma was developed and validated. Unlike the already published methods, the present method features high sensitivity, throughput, reproducibility and precision. Moreover, this method does not have any matrix effect like abnormalities. We believe that this method is a useful tool for the determination of NVP in human plasma. This method can be successfully applied for bio-equivalence study of NVP.

\section{Acknowledgements}

The authors would like to thank Ms Koyel Ghosh, Mr. Deepak Rupala and Ms. Saumya Bahadur for their contributions to the improvement of the work described herein.

\section{References}

1. Mirochnick M, Clarke DF, Dorenbaum A (2000) Nevirapine: pharmacokinetic considerations in children and pregnant women. Clin. Pharmacokinet 39: 281 293.

2. Jackson JB, Musoke P, Fleming T, Guay LA, Bagenda D, et al. (2003) Intrapartum and neonatal single-dose nevirapine compared with zidovudine for prevention of mother-to-child transmission of HIV-1 in Kampala, Uganda: 18-month follow-up of the HIVNET 012 randomised trial. Lancet 362: 859-868.

3. Taha TE, Kumwenda NI, Gibbins A (2003) Short postexposure prophylaxis in newborn babies to reduce mother-to-child transmission of HIV-1: NVAZ randomised clinical trial. Lancet 362: 1171-1777.

4. Stringer JSA, Rouse DJ, Sinkala M, Marseille EA, Vermund SH, et al. (2003) Nevirapine to prevent mother-to-child transmission of HIV-1 among women of unknown serostatus. Lancet 362: 1850-1853.

5. Jourdain G, Ngo-Giang-Huong N, La Coeur S, Bowonwatanuwong C, Kantipong P, et al. (2004) Intrapartum Exposure to Nevirapine and Subsequent Maternal Responses to Nevirapine-Based Antiretroviral Therapy. N Engl J Med. 351: 229-240.

6. Gibbs JE, Gaffen Z, Thomas SA (2006) Nevirapine Uptake into the Centra Nervous System of the Guinea Pig: An in Situ Brain Perfusion Study JPET 317: 746-751.
7. Pav JW, Rowland LS, Korpalski DJ (1999) HPLC-UV method for the quantitation of nevirapine in biological matrices following solid phase extraction. J Pharm Biomed Anal 20: 91-98.

8. Marchei E, Valvo L, Pacifici R, Pellegrini M, Tossini G et al (2002) Simultaneous determination of zidovudine and nevirapine in human plasma by RP-LC. J. Pharm Biomed Anal. 29: 1081-1088.

9. Silverthorn CF, Parsons TL (2005) A validated new method for nevirapine quantitation in human plasma via high-performance liquid chromatography. Biomed Chromatogr. 20: 23-27.

10. Kabra V, Agrahari V, Karthikeyan C, Trivedi P (2009) Simultaneous quantitative determination of zidovudine and nevirapine in human plasma using isocratic reverse phase high performance liquid chromatography Trop J Pharm Res. 8 : $79-86$

11. van Heeswijk RP, Hoetelmans RM, Meenhorst PL, Mulder JW, Beijnen JH (1998) Rapid determination of nevirapine in human plasma by ion-pair reversed-phase high-performance liquid chromatography with ultraviolet detection. J Chromatogr B Biomed Sci Appl. 25: 395-399.

12. Ramachandran G, Hemanthkumar AK, Kumaraswami V, Swaminathan S (2006) A simple and rapid liquid chromatography method for simultaneous determination of zidovudine and nevirapine in plasma. J Chromatogr B 843: 339-344.

13. Venkata Kumar CH, Ananth Kumar D, Rao JVLNS (2010) A New Validated RPHPLC Method for the Determination of Nevirapine in Human Plasma. E-Journal of Chemistry $7: 821-826$.

14. Kappelhoff BS, Rosing H, Huitema ADR, Beijnen JH (2003) Simple and rapid method for the simultaneous determination of the non-nucleoside reverse transcriptase inhibitors efavirenz and nevirapine in human plasma using liquid chromatography. J Chromatogr B Analyt Technol Biomed Life Sci 792: 353-362.

15. Li Z, Ding C, Ge Q, Zhou Z, Zhi X, et al. (2010) Simultaneous determiniation of lamivudine, stavudine and nevirapine in human plasma by LC-MS/MS and its application to pharmacokinetic study in clinic. Biomed Chromatogr 24 926-934.

16. Notari S, Mancone C, Alonzi T, Tripodi M, Narciso P, et al. (2008) Determination of abacavir, amprenavir, didanosine, efavirenz, nevirapine, and stavudine concentration in human plasma by MALDI-TOF/TOF. J Chromatogr B Analyt Technol Biomed Life Sci 863: 249-257.

17. Chi J, Jayewardene AL, Stone JA, Aweeka FT (2003) An LC-MS-MS method for the determination of nevirapine, a non-nucleoside reverse transcriptase inhibitor, in human plasma J Pharm Biomed Anal 31: 953-959.

18. Laurito TL, Santagada V, Caliendo G, Oliveira CH, Barrientos-Astigarraga RE, et al.(2002) Nevirapine quantification in human plasma by high-performance liquid chromatography coupled to electrospray tandem mass spectrometry. Application to bioequivalence study J Mass Spectrom 37: 434-441.

19. Ghosh C, Singh RP, Inamdar S, Mote M, Chakraborty BS (2009) Sensitive, Selective, Precise and Accurate LC-MS Method for Determination of Clonidine in Human Plasma Chromatographia, 69: 1227-1232.

20. Ghosh C, Jha V, Ahir R, Shah S, Shinde CP, et al. (2010) A rapid and most sensitive liquid chromatography/tandem mass spectrometrymethod for simultaneous determination of alverine and its major metabolite, para hydroxy alverine, in human plasma: application to a pharmacokinetic and bioequivalence study Drug Test Anal 2: 284-291.

21. Ghosh C, Shinde CP, Chakraborty BS (2010) Ionization Polarity as a Caus of Matrix Effects, its Removal and Estimation in ESI-LC-MS/MS Bio-analysis J Anal Bioanal Techniques 1: 106.

22. Guidance for Industry, Bioanalytical Method Validation Food and Drug Administration, Center for Drug Evaluation and Research (CDER), 2001. 